\title{
M igração e mobilidade de brasileiros através e além da fronteira Brasil-Guiana Francesa: novas sociabilidades
}

\author{
Carmentilla das Chagas Martins ${ }^{1}$ \\ Eliane Superti ${ }^{2}$ \\ Manoel de Jesus de Souza Pinto
}

\section{Resumo}

Este artigo tem como objetivo apresentar os processos de mobilidade e as dinâmicas migratórias na fronteira internacional franco-amapaense. Metodologicamente se propõe uma abordagem diferente em relação aos estudos empíricos pautados em análises quantitativas. Busca-se perceber - com novas metodologias de estudo ligadas a prática qualitativa da pesquisa-ação e histórias de vida - dinâmicas migratórias no Platô das Guianas. Considera-se que tanto a mobilidade como a migração são processos que se particularizam quando se desenrolam em espaço de fronteiras. 0 artigo está organizado em três partes: a primeira contextualiza o espaço social fronteiriço; a segunda reflete sobre a mobilidade na fronteira Brasil-Guiana Francesa; por último se analisa as novas práticas migratórias. Entende-se que a partir desses encontros de sociedades e culturas é possível identificar novas sociabilidades.

Palavras-Chave: Migração; Mobilidade; Fronteira Brasil-Guiana Francesa; Sociabilidades

\footnotetext{
${ }^{1}$ Professora e pesquisadora da Universidade Federal do Amapá/UNIFAP. Doutora em Ciências Sociais pela Universidade Federal do Pará/UFPA. E-mail: carmentilla@unifap.br ${ }^{2}$ Professor pesquisador da Universidade Federal do Amapá/UNIFAP. Doutor em Ciências Socioambientais pela Universidade Federal do Pará/UFPA. Pós-doutorado no CNRSGuyane vinculado ao Observatoire Hommes-Milieux. E-mail: manoel-pinto@bol.com.br

${ }^{3}$ Professora pesquisadora da Universidade Federal do Amapá/UNIFAP. Doutora em Ciências Sociais pela Universidade Federal de São Carlos/UFSCAR. Realizou estágio de pós-doutorado em Ciência Política pela Universidade Federal Fluminense/Escola Superior de Guerra. E-mail esuperti@unifap.br
} 


\section{Migration and mobility of Brazilians through and beyond the Brazil-French Guiana border: new sociabilities.}

\section{Abstract}

This article has as objective to present the processes of mobility and the migration dynamics in the French Guiana-Amapá international border. Methodologically it is proposed a different approach in relation to the empirical studies guided by quantitative analysis. It looks for perceiving - with new study methodologies related to qualitative practice of action research and life stories - migration dynamics in the Plateau of the Guianas. It is considered that both the mobility and migration are processes that particularize themselves when unfolding in the space of borders. The paper is organized into three parts: the first one contextualizes the border social space; the second reflects on mobility in Brazil-French Guiana border; Finally the new migratory practices are analyzed. It is understood that from these meetings of societies and cultures it is possible to identify new sociabilities.

Keywords: Migration; Mobility; Brazil-French Guiana border; Sociabilities

Este artigo nasce de uma constatação: a forte presença de brasileiros na Guiana Francesa. É bastante comum no estado do Amapá conhecer pessoas que em algum momento de sua vida deslocaram-se para Guiana Francesa em busca de melhor oportunidade de trabalho e renda. Neste sentido novos fenômenos (linguísticos, culturais e econômicos) são identificados e os próprios atores envolvidos no processo criam e recriam estratégias para satisfazerem suas subjetividades. É justamente na dinâmica destas novas relações sociais que este artigo pretende se envolver. As perguntas que orientam este artigo inserem-se num conjunto mais abrangente de preocupações, a saber: quais 
aspectos qualificam a dinâmica migratória na fronteira do Brasil com a Guiana Francesa? A mobilidade de brasileiros através e além da fronteira com a Guiana Francesa tem relação com os atuais aspectos que caracterizam a migração transfronteiriça? Quais desdobramentos dessas dinâmicas populacionais para as interações sociais entre moradores dos dois lados da fronteira? 0 retorno ou mesmo a deportação de trabalhadores brasileiros da Guiana Francesa tem relação com as transformações no mundo do trabalho desencadeadas pela globalização?

Nos estudos mais atualizados sobre mobilidade humana no espaço, o migrante vivencia uma experiência que faz parte do senso comum: a de "desaparição" e "reaparição" de territórios e identidades; de fragmentação e agregação de parcelas do espaço; de ruptura e continuidade na diversidade de interpenetrações entre indivíduos singulares e coletivos. Essas experiências são ao mesmo tempo resultante e motor da sustentabilidade da mobilidade e das prática migratórias com direção a Guiana Francesa. É justamente neste núcleo de interesses que se faz algumas incursões empírico-qualitativas sobre o assunto tendo como plataforma um conjunto de trabalhos de campo realizados ao longo de 10 anos de pesquisas na região do Platô das Guianas. 0 objetivo é apresentar os processos de mobilidade, as dinâmicas migratórias na fronteira internacional Para tanto, o artigo está organizado em três partes, a saber: um breve histórico sobre a construção social da fronteira Brasil-Guiana Francesa; a seguir uma discussão sobre a mobilidade e as práticas migratórias nessa região fronteiriça; por último, uma análise dos novos fenômenos migratórios.

\section{Espaço social fronteiriço Franco-Amapaense.}

Em relação ao Amapá e a Guiana Francesa cabe chamar atenção para algumas similitudes que os aproxima, tais como: 1ํ) Amapá e a Guiana Francesa apresentam uma significativa cobertura vegetal em seus territórios o que revela pouca degradação do 
patrimônio natural; $2^{\circ}$ ) em termos infraestruturais têm níveis inferiores as suas correspondentes nacionais e um incipiente desenvolvimento socioeconômico; $3^{\circ}$ ) no cenário de suas nações elas são periferias em relação aos centros decisórios e dependentes de recursos financeiros externos.

Cabe ressalvar, que as disparidades não se limitam a diferenças econômicas, mas também aquelas relativas ao acesso a serviços públicos, tecnologias, infraestrutura e oportunidades de inserção no mercado de trabalho. Por exemplo, em Oiapoque 9,8 \% da população vive entre a linha da indigência e pobreza, e 24,1\% abaixo na linha de indigência, o que dá um total de 33,9\% oiapoquenses pobres e indigentes (BRASIL/PORTALODM, 2015, p. 2). ${ }^{4}$

Na fronteira do Amapá com a Guiana Francesa, segundo dados apresentados em estudo comparativo do CEROM - Contas Econômicas Rápidas para os Departamentos do Ultramar ${ }^{5}$, o produto interno bruto por habitante é de $\mathrm{R} \$ 35.199,12$ (€ 13.372), enquanto no Amapá o mesmo índice é de R\$3.854; o que, aliás, imprime maior pressão econômica dos brasileiros em direção à Guiana Francesa (GRENIER, 2011).

Do lado brasileiro localiza-se a cidade de Oiapoque e do lado francês a cidade de Saint-Georges, essas coletividades são separadas por critérios relacionados à soberania; nacionalidade e etnicidade; organização política, administrativa, institucional; mas também são muito próximas em termos físicos e em virtude disso há intenso deslocamento de pessoas entre os dois lados da fronteira que provoca um elevado grau de interação entre seus habitantes. Esse contexto classifica Oiapoque e Saint Georges como cidades-gêmeas.

${ }^{4} \mathrm{O}$ cálculo é feito por meio da soma da renda de todas as pessoas do domicílio, e o total dividido pelo número de moradores, sendo considerado abaixo da linha da pobreza os que possuem renda per capita até $\mathrm{R} \$ 140,00$. No caso da indigência, este valor será inferior a R\$ 70,00 (BRASIL/PORTALODM, 2013).

${ }^{5}$ Estudo em parceria com a AFD, o IEDOM e o INSEE e tem como principal objetivo a promoção da análise econômica das coletividades Ultramarinas da República da França. 
Ainda que a Guiana Francesa não seja um país, ${ }^{6}$ e sim um departamento de ultramar da França, a cooperação fronteiriça franco-brasileira deve ser concebida nesse contexto continental, no entanto como caso particular. Várias ações de planejamento e gestão foram estruturadas pelo governo brasileiro, tendo por foco a dinamização das regiões e a melhor distribuição das atividades produtivas nos territórios, sendo elaborados mecanismos de planejamento, financiamento e coordenação interinstitucionais favoráveis à convergência da ação pública para obtenção de sinergias e de complementaridades com impacto significativo (SENRA, 2010).

Figura 1 - Unidades administrativas do Estado do Amapá e da Guiana Francesa.

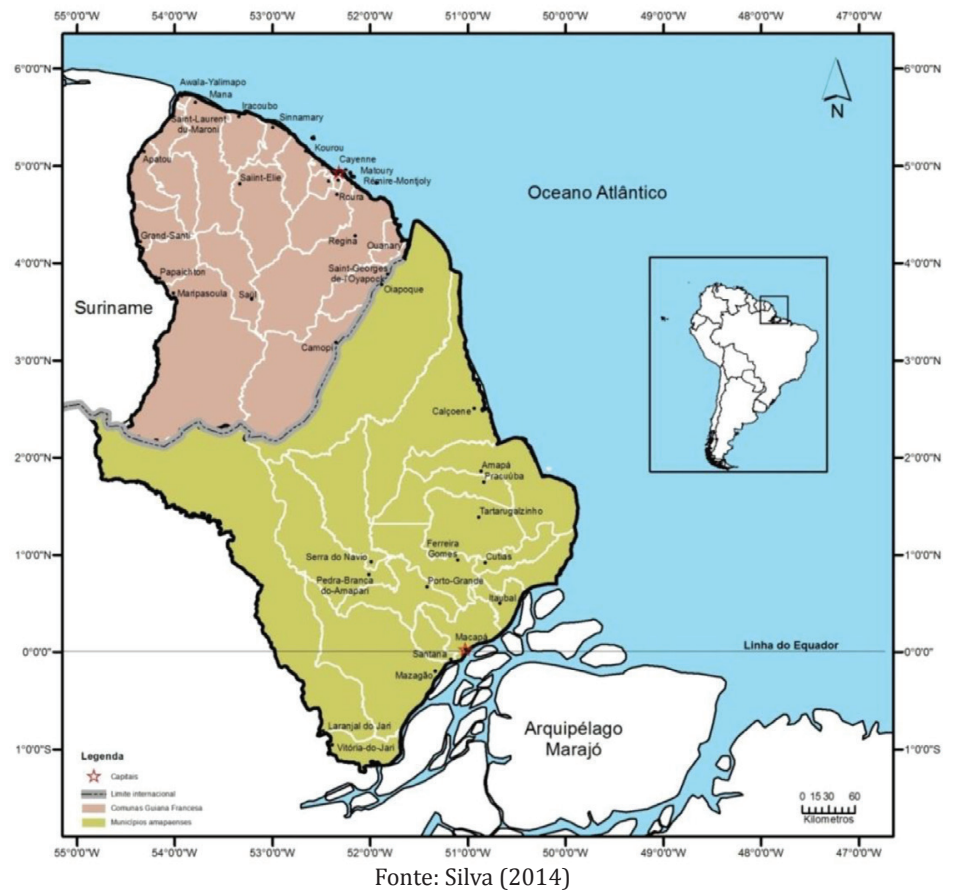

${ }^{6}$ No contexto sul-americano, a Guiana Francesa era considerada uma lembrança constante do colonialismo francês, condição frequentemente denunciada pelo Brasil em fóruns multilaterais regionais (LESSA, 2000; GRANGER, 2011). 
A condição fronteiriça dessa região guarda suas especificidades culturais e um contexto socioeconômico singular. Do lado do Amapá, a condição fronteiriça começou a ser construída desde o período colonial nas disputas entre Portugal e França e depois entre Brasil e França. Modernamente, a configuração de seu território foi marcada pelo desmembramento da região como parte do estado do Pará em 1943 para a criação do Território Federal do Amapá (TFA) e posteriormente sua transformação em estado da federação brasileira em 1988.

A composição geográfica e política do estado lhe confere uma condição singular de espaço simultaneamente estratégico e periférico (PORTO, SILVA, 2010). Sua configuração estratégica é decorrente de sua posição fronteiriça com a França, país membro da comunidade econômica europeia. Isso é entendido como fator de ampliação das interações entre Brasil-França, de sua vinculação geográfica ao Platô das Guianas, da preservação da floresta nativa e da imensa sociobiodiversidade que possui. Outro aspecto importante é sua posição as margens do rio Amazonas o que lhe oferece condição de recepção de navios de grande calado. Todos esses elementos que compõe o potencial estratégico do Amapá ganharam acentuada relevância diante das políticas públicas estatais de integração física das fronteiras amazônicas, presentes nos planos plurianuais (PPA) nacionais desde meados da década de 1990, e da Iniciativa de Integração Regional Sul Americana (IIRSA). Ambas as políticas pretendem através da realização e grandes obras infraestruturais - no Amapá o asfaltamento da BR 156 que liga Macapá ao Oiapoque, a construção da ponte binacional Oiapoque/BR - Saint Georges/FR, a construção de três hidrelétricas com ligação energética com Tucuruí e modernização do porto e aeroporto - integrar a região ao mercado sul americano.

Sua condição periférica é fruto da distância dos grandes centros econômicos e políticos nacionais, de seu isolamento geográfico dado ausência de acesso rodoviário com os demais estados do país. Tal condição periférica é agravada pela fragilidade estrutu- 
ral de sua economia, pouco diversificada, extrativista e produtora de commodities, além de fortemente marcada pela importância do poder público na oferta de empregos. Apesar da constante presença do capital internacional e das grandes empresas de capital intensivo desde a época do extinto território na exploração de recursos naturais ${ }^{7}$ (principalmente minério). Essa condição se acentua também pela escassez de recursos humanos qualificados, especialmente na área tecnológica, e pelas debilidades de qualificação local. Associam-se a estas características as dificuldades políticas de representação e articulação no cenário nacional dos interesses locais e a manutenção de práticas clientelistas na administração do estado e dos municípios que comprometem o planejamento em longo prazo e a organização coletiva.

O estado do Amapá é ainda marcado por características específicas de sua condição de ex-território federal e de estado amazônico. A principal delas diz respeito ao controle de suas terras. Seis esferas institucionais atuam sobre o uso e a ocupação dessas terras e apenas $40.605 \mathrm{~km} 2(22,27 \%)$ do território está sob o controle do estado do Amapá em um total de 143.453,7 km2. Esse fato limita consideravelmente a capacidade do governo do Amapá em promover seu ordenamento. Soma-se a isso o fato de que atualmente, $72 \%$ do território do Estado são protegidos pela demarcação de terras indígenas (10\%) e pela criação de áreas de proteção ambiental estadual, federal e privada (62\%). Estas características têm impactado no processo de urbanização amapaense, pois impede a população de ocupar áreas protegidas e os munícipios vivenciam a sobreposição dos territórios, ou seja, as áreas dos municípios amapaenses juridicamente delimitadas são controladas pelo governo federal ou estadual, onde o Prefeito possui nenhuma ou pouca capacidade de gestão.

\footnotetext{
${ }^{7}$ O Amapá teve o primeiro grande empreendimento minerador da Amazônia brasileira com a empresa ICOMI na década de 1950. Ver DRUMMOND, José Augusto; PEREIRA, Mariângela de Araújo Póvoas. O Amapá nos tempos do manganês: um estudo sobre o desenvolvimento de um estado amazônico 1943-2000. Rio de Janeiro: Garamond, 2007.
} 
Na Amazônia brasileira em geral e no Amapá em particular essa é uma séria limitação, pois, as instituições político-administrativas municipais constituem, por vezes, nas únicas presenças efetivas do Estado em vastas porções do seu território. As cidades representam o lócus por excelência das múltiplas articulações comunitárias, das sedes das empresas voltadas à exploração dos recursos naturais, das forças de atração dos fluxos migratórios. Elas são, também, o lugar de concentração de considerável parcela da população e dos mais agudos problemas sociais e ambientais.

Como parte desse contexto, o município do Oiapoque sofre a virtualidade de sua capacidade de gestão, pois, suas terras estão sob jurisdição federal e dividias entre áreas de proteção ambiental como o Parque Nacional Montanhas do Tumucumaque e Parque Nacional do Cabo Orange e terras indígenas Galibi, Juminá (Galibis e Karipunas) e Uaçá (Karipunas). A cidade vivencia, também, graves problemas de infraestrutura urbana como saneamento básico inexistente, precárias condições de habitabilidade, alta densidade de resíduos sólidos sem coleta adequada, esgoto a céu aberto e ausência de mobilidade urbana. Muitos destes problemas estão vinculados a aplicação das políticas de ordenamento do uso do território no estado sem considerar as necessidades das áreas urbanas ou a realização de seu prévio planejamento (TOSTES, 2010).

O município do Oiapoque foi criado em 1945, ainda na época do território federal, para garantir a ocupação da fronteira por meio da colonização induzida por políticas públicas e estratégias geopolíticas de segurança nacional como a construção da BR 156. Passado mais de meio século de existência, o município é o quarto maior do estado com 20.426 habitantes. Seu crescimento demográfico foi de 50\%, entre 2000 a 2010, de acordo com o levantamento de Santos (2013). A explicação para o aumento se liga pavimentação parcial da BR 156, que facilitou o acesso, a construção da ponte binacional e os anseios de imigração para a 
Guiana Francesa. As estatísticas sobre essa população apontam um alto percentual de miséria. 9,8 \% da população vive entre a linha da indigência e pobreza e $24,1 \%$ estão abaixo na linha de indigência, o que dá um total de 33,9\% oiapoquenses pobres e indigentes (BRASIL/PORTALODM, 2013, p. 2) ${ }^{8}$.

A infraestrutura da cidade não atende as demanda de seu crescimento populacional e a precariedade da condição urbana é um fato incontestável. As vias públicas do núcleo urbano são irregularmente asfaltadas, as construções habitacionais são precárias, os serviços públicos de saúde, educação e segurança pública são débeis e refletem a fragilidade do poder público local em atender as necessidades básicas da população.

Apesar de suas graves deficiências infraestruturais, a cidade tem uma vida agitada. Oiapoque é uma cidade que não para e que possui um tempo próprio: o de fronteira. A movimentação dos catraieiros ${ }^{9}$ que transportam pessoas e cargas é intenso e constante. Bares e boates funcionam todos os dias até de madrugada, o comércio clandestino e o câmbio negro acontecem nas vias públicas, principalmente na beira rio. A prostituição como fonte de trabalho quase institucionalizada movimenta bares e hotéis. 0 comércio regular é totalmente livre de fiscalização. Diariamente centenas de brasileiros e guianenses, contrabandistas, garimpeiros, atravessadores, índios, agricultores chegam à cidade para fazer compras. A diferença cambial estimula a procura por gêneros de primeira necessidade pelos guianenses, principalmente pela carne brasileira. 0 comércio se movimenta com três moedas, ouro, euro e real.

${ }^{8} 0$ cálculo é feito por meio da soma da renda de todas as pessoas do domicílio, e o total dividido pelo número de moradores, sendo considerado abaixo da linha da pobreza os que possuem renda per capita até $\mathrm{R} \$ 140,00$. No caso da indigência, este valor será inferior a R\$ 70,00 (BRASIL/PORTALODM, 2015).

${ }^{9}$ Pilotos das catraias. Catraias são pequenas embarcações com motor que atravessam o rio Oiapoque com pessoas e mercadorias, ligando as cidades gêmeas. 
Oiapoque é uma cidade de fronteira, e como tal guarda muitos segredos. Seu funcionamento se rege por duas lógicas contraditórias: a primeira atende, na medida do possível, às exigências jurídicas e políticas do Estado brasileiro. Possui escolas, delegacias, postos médicos, prefeitura, fórum e instituições bancárias. A segunda forma de funcionamento é a clandestina, vivenciada nos becos, nos bares, nas saídas ilegais para Caiena e garimpos da região, onde prevalece a lei do silêncio e do mais forte. Para se viver na fronteira é necessário conhecer os códigos, as normas e as regras que circulam nas relações sociais entre seus moradores, e isto vale mesmo para aqueles que apenas "passam" pela cidade.

O município, em um olhar rápido, se parece mesmo com um entreposto comercial. Por ser a porta de entrada entre o território francês e o Brasil e de ser cercada de garimpos, a maioria clandestina, o município historicamente aprendeu a conviver com aventureiros de toda parte do Brasil e com muito dinheiro circulante.

Do outro lado do rio Oiapoque, a condição fronteiriça da Guiana Francesa também foi construída pelas disputas coloniais entre franceses, holandeses e portugueses. A chegada do Império colonial francês nessas terras amazônicas se deu em 1604 e apesar das intensas disputas entre metrópoles europeias, a Guiana viveu sob o estatuto de colônia francesa até 1946. Localizada ao norte do continente sul-americano, a Guiana Francesa faz fronteira com o Suriname (antiga Guiana Holandesa) a oeste e com o Brasil (antiga colônia portuguesa) ao sul. A costa é banhada pelo oceano Atlântico.

A lei de assimilação decretada em 1946 transformou e antiga colônia em Departamento Ultramar da República Francesa, juntamente com as ilhas da Martinica, de Guadalupe - nas Antilhas - e a da Reunião, no oceano Índico. A partir de então, os habitantes passaram a ter o estatuto de cidadãos franceses e as regiões tornaram-se território nacional francês. Seus espaços político 
e institucional foram organizados segundo os mesmos moldes dos demais departamentos da França. Essa solução atendeu à reivindicação das elites locais (FARRAUDIÈRE, 1989), favoreceu a estruturação dos serviços públicos (educação, saúde etc.) e a ampliação dos benefícios sociais. Na Guiana francesa, o intenso fluxo de recursos vindos do Estado francês desde a departamentalização - e mais recentemente da União Europeia - possibilitou um nível de vida superior ao dos demais territórios amazônicos apesar de inferior ao da França hexagonal. Não foi, contudo, capaz de produzir um projeto socioeconômico de integração e o desenvolvimento local que rompesse com os profundos laços de dependência.

Mesmo tendo representado um importante avanço sociopolítico, a transformação em Departamento não significou uma ruptura da fase anterior. Entre esses dois momentos da história guianense existe uma linha de continuidade no fato de que o Estado francês controla econômica, administrativa e militarmente toda a região da Guiana, aliás, no uso do termo "metrópole" pelo qual os habitantes da Guiana se referem à França hexagonal reflete isso claramente.

A população da Guiana conta com 236.250 habitantes distribuídos de forma muito desigual. A densidade populacional média em 2011 foi de apenas 2,8 habitantes por $\mathrm{km}^{2}$, uma grande porção do território está desabitada o que justifica o fato de $96 \%$ do território ter sua cobertura florestal preservada. A maioria da população se concentrada no litoral e ao longo dos principais rios de fronteira. (INSEE, 2012)

Quanto a sua condição econômica, o garimpo sempre foi um elemento importante, apesar de outras iniciativas, principalmente no setor primário antes da abolição da escravidão em 1848. A atração de garimpeiros e comerciantes das Antilhas e dos países vizinhos ajudaram a formar o mosaico cultural que hoje compõe a sociedade guianense. 0 garimpo promoveu também a proximi- 
dade com parte das populações quilombolas instalada na fronteira com a então Guiana Holandesa (Suriname), os bushinengue ou noirs marrons, cujas habilidades na navegação dos rios eram muito úteis para exploração e escoamento do metal. Todavia, o desenvolvimento econômico promovido pela garimpagem foi efêmero. Favoreceu, contudo, o enriquecimento de algumas famílias guianenses, de comerciantes antilhanos e franceses, permitiu também fortalecer o processo de urbanização da cidade de Caiena (JOLIVET, 1997). Vale ressaltar que o garimpo é ainda hoje muito explorado, em sua maioria de modo clandestino e com meios precários, causando graves problemas ambientais, de violência, além de evasão de recursos.

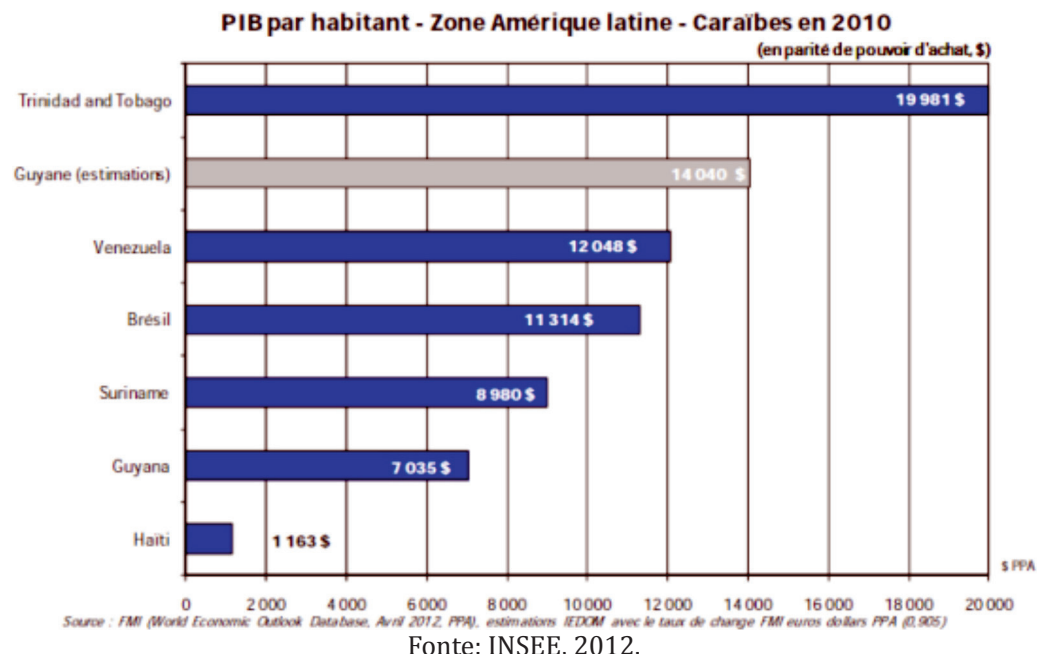

A economia da Guiana Francesa vivenciou um importante impulso a partir 1965, com a instalação do projeto tecnológico do Centro Espacial Guianense (CEG) em Kourou. Rapidamente o centro se tornou o elemento mais dinâmico da economia local. Sua construção implicou também no aumento significativo dos fluxos imigratórios, principalmente de brasileiros, para a Guiana. Mas, o CEG não livrou a Guiana de sua extrema dependên- 
cia, embora tenha sido importante para o estabelecimento de empresas do setor secundário na região. Os bens de consumo e equipamentos, na grande maioria, ainda hoje, são importados da França metropolitana, com exceção de alguns produtos locais. Mesmo assim, entre os anos de 1999 a $2007^{10}$, o Produto Interno Bruto (PIB) da Guiana cresceu 4,3\% ao ano em termos reais, contra $2,2 \%$ ao ano em média nacional. Segundo o INSEE, essa vitalidade está ligada principalmente ao dinamismo demográfico que suporta a demanda interna e a atividade espacial, registrados como serviços de exportação, pois os setores tradicionais, como agricultura, construção civil e comércio continuam frágeis e dependentes.

O PBI per capita da Guiana Francesa é 48\% do nacional, contudo quando comparado com o PBI dos países que compõe a sub-região em que está inserida, a Guiana Francesa fica em segundo lugar no ranking, como demonstra o gráfico anteriormente apresentado. Esse dado explicita que embora a Guiana Francesa não possa ser considerada um Departamento Ultramar economicamente desenvolvido, no contexto regional suas condições de renda per capita são superiores a de países com dimensões muito mais expressivas e economias mais robusta e complexa, como o Brasil, por exemplo. $\mathrm{O}$ Índice de Desenvolvimento $\mathrm{Hu}$ mano (IHD) também aponta nessa mesma direção. A média dos países da América Latina e Caribe no IHD é de 0,731 enquanto que da Guiana é de 0,806 (INSEE, 2012). Evidentemente que o alcance desse índice está fortemente atrelado aos serviços da administração pública oferecidos na Guiana Francesa como educação, saúde e saneamento básico, infraestrutura urbana e seguridade social, garantidos pelo governo metropolitano.

O crescimento populacional, que dinamiza a economia, provoca também um grave problema social na Guiana Francesa, o

${ }^{10}$ Dados obtidos no relatório de 2012 do INSEE. Informações mais recentes não estão disponíveis. 
desemprego. Nos últimos 12 anos, segundo o INSEE (2012), o crescimento demográfico da Guiana manteve uma taxa de 3,5\% ao ano. Essa taxa foi bem mais alta na década de 1980 e inicio de 1990 por força dos fluxos migratório e se estabilizou no primeiro de decênio deste século. Chama a atenção o fato de que a Guiana é a região mais jovem da França. Os jovens com menos de 20 anos representam 44,4\% da população. A fragilidade da economia guianense em absorver o fluxo de crescimento da população provoca uma taxa de desemprego significativamente alta de 21\% (INSEE, 2012). 0 desemprego atinge principalmente as mulheres, $60 \%$ no total de desempregados, e os jovens entre 24 e $45 \operatorname{anos}^{11}$.

Este é um paradoxo da Guiana Francesa: seu dinamismo demográfico lhe permitiu o crescimento econômico, pautado principalmente na demanda interna, mas ao mesmo tempo inflou a taxa de desemprego, sobrecarregando os serviços de seguridade social. As politicas públicas francesas e europeias não têm conseguido impactar para a reversão desse quadro. A ausência de estruturação interna dos principais setores econômicos e a dependência administrativa e econômica da França hexagonal dificulta o desenvolvimento endógeno. Além disso, o tecido econômico é, na sua maioria, constituído por empreendimentos familiares ou por poucas microempresas em cada setor, com competências e capacidades financeiras limitadas. Outra situação que chama a atenção é a crescente militarização da Guiana Francesa. Na estrada que liga Saint George na fronteira com o Brasil com a capital Caiena é constante presença de soldados. As diligências, as rondas, as operações na fronteira, as abordagens realizadas contra imigrantes, a presença dos Legionários no território guianense, fazem da Guiana Francesa uma verdadeira área militar, e de rígido controle social.

${ }^{11}$ Dados retirados da tabele structure de chômage. Ver INSEE. Guyane: Rapport anuel de 2011. Paris: PRIM, 2012, pág. 32. 
A questão populacional na Guiana Francesa traz ainda outros elementos importantes de sua condição fronteiriça. Os constantes fluxos migratórios e sua colonização levaram a formação de uma sociedade peculiar e oferece a ilustração das tensões entre a formação de um conjunto de tipo nacional e a afirmação de identidades étnicas singulares. Se há uma identidade coletiva predominante, uma guianidade, ela se apoia principalmente na comunidade crioula, que historicamente gozou do maior peso demográfico e do poder político local.

Essa dinâmica se modifica a partir dos anos 1970, com a perda do peso demográfico do grupo creole acarretada pelos fluxos migratórios recentes (MAM-LAM-FOUCK, 1996, 1997), as desconfianças em relação aos efetivos benefícios da departamentalização e a presença no debate público das reivindicações identitárias dos povos indígenas e bushinengue. Os creoles (elites urbanas) partem em busca de definir a substância de sua 'creolidade', num processo de reconstrução identitária em que a ancestralidade e as raízes são valorizadas, determinando a reconciliação, no âmbito do imaginário, dos grupos 'primitivos' antes rejeitados. No momento atual, a fragilidade da posição de dominação, ameaçada pela entrada de novos atores, e a alta taxa de desemprego criam reações defensivas que favorecem a atitude de recusa ao estrangeiro.

Podemos considerar a Guiana Francesa como uma sociedade de imigração. Ela é marcada pela convivência justaposta entre várias sociedades de peso demográfico e político muito desigual. A imagem de um 'mosaico' é comumente utilizada para descrever sua população.

Inserida nesse contexto está a comuna franco guianense de Saint-George, nas bordas do rio Oiapoque e na fronteira internacional com o Brasil. É uma pequena cidade com aproximadamente 5 mil habitantes. Sua estrutura urbana difere significativamente da vizinha Oiapoque, as ruas do núcleo urbano são 
asfaltadas e limpas, a cidade tem água tratada e rede de esgoto e coleta regular de lixo, mas parte dos resíduos é descartada no rio Oiapoque. As construções são regulares e os serviços públicos de saúde, segurança e educação atendem as demandas básicas da pequena população. A cidade é aparentemente pacata e entediante para os padrões oiapoquenses, apenas uma casa noturna foi identificada. Porém, vários incidentes são registrados pela polícia local, como pequenos furtos e bebedeiras - parte realizada por brasileiros. Segundo Pinto, (2012), a repressão é intensa e ele exemplifica com o testemunho dos catraieiros que afirmaram, em entrevista de campo, que quando são pegos no comércio de Saint-Georges, sem identificação são castigados pela polícia francesa em praças públicas, geralmente são amarrados por quase três horas.

As poucas casas de comércio varejista são quase todas controladas por imigrantes chineses, a rede de hotéis e restaurantes é incipiente. 0 movimento das catraias é tão intenso como na cidade do Oiapoque e o policiamento frequente. Porém, é tolerada a presença de brasileiros sem visto na cidade desde que não ultrapassem os limites do núcleo comercial. 0 controle de entrada no território acontece na saída da cidade. 0 fluxo de transeuntes na fronteira também alimenta o comercio de transporte das vans entre Saint Georges e Caiene, principalmente.

A relação entre as duas cidades gêmeas é intensa. Em Saint George fala-se francês, creole e português, mas a moeda é apenas o euro. Outro elemento que chama a atenção é a mobilidade indígena de diferentes etnias presentes no espaço geográfico fronteiriço. Em sua maioria são indígenas Galibi do Oiapoque e Galibi Marworno que transitam de ambos os lados do limite internacional. Turistas franceses e guianenses são comuns em transito para o Brasil favorecidos pela disparidade entre o euro e o real. Já os brasileiros atravessam para realizar pequenas trocas comerciais - compra e venda de bens de consumo imediato (principalmente carne de gado) ou compra de produtos tecno- 
lógicos mais acessíveis do lado franco-guianense ou para visitar familiares e amigos e participar de confraternizações.

As zonas fronteiriças são zonas de empréstimos e apropriações culturais. Essas fronteiras tanto podem se configurar como lugar de controle como de transgressão, tanto nas fronteiras geopolíticas, quanto nas culturais e subjetivas (RODRIGUES, 2006). Oiapoque e Saint George, como quase todas as cidades localizadas em área de fronteira, oscilam entre o efêmero e o permanente, o local e o global, enfim, possuem uma realidade própria e uma zona cultural que ao mesmo tempo recebe influência, e influencia atitudes e comportamentos culturais. Fronteiras são espaços sociais interligados, produtos de interstícios culturais que se revelam, às vezes, de forma tácita e subjetiva. As relações sociais identificadas na cidade de Oiapoque e em Saint Georges mostram estratégias de sobrevivência de instituições e sujeitos sociais, como forma de manter o funcionamento das cidades.

\section{D inâmicas e mobilidades na fronteira entre 0 iapoque e Guiana Francesa}

Para a discussão sobre as dinâmicas e mobilidades na fronteira estudada adotamos a priori, os conceitos de circularidade e/ou pendularidade no esforço de realizar sua classificação. Contudo, esses termos não contemplaram toda complexidade os fenômenos analisados, e foi preciso expandir seus significados. Em linhas gerais, de modo limitado, a circularidade e a pendularidade se definem pelo tempo de afastamento do indivíduo de sua residência: sendo circular quando o afastamento dura trinta dias; pendular quando ocorre diariamente (OLIVEIRA, 2011). Porém, no caso de Oiapoque, não é exatamente isso que acontece.

Os migrantes que vêm de outros estados brasileiros (principalmente do Pará e do Maranhão) ficam em situação de espera em Oiapoque aguardando a conveniência de seguir para a Guiana 
Francesa (em especial para trabalhar nos garimpos), de modo que para tipificar essa mobilidade como circular haveria de se estabelecer um período de permanência que qualificasse a cidade como domicílio-base antes de iniciar-se o deslocamento para a Guiana Francesa, mas não existe uma regularidade que permitia essa tipificação. Por outro lado, também é muito limitado considerar pendular a mobilidade no rio Oiapoque ao se ter em conta que implica em períodos maiores ou menores que um dia e envolve práticas dos atores referentes a percursos entre o domicílio e o lugar de trabalho, mas também outros trajetos relativos às condições de acesso a saúde, a educação, a lazer e outros bens e serviços dentre muitos aspectos da vida cotidiana.

Em síntese, os percursos podem desenrolar-se em distintos tempos, por exemplo, a travessia para Saint-Georges dura em média vinte minutos, mas não é possível chegar a Vila Brasil em menos de cinco horas. Os afastamentos em relação à Oiapoque podem durar alguns minutos, horas, dias, ou um mês.

Todavia, os deslocamentos para Guiana Francesa podem implicar em mudança de domicílio por um tempo mais prolongado ou mesmo permanente, trata-se de brasileiros documentados que residem na Guiana Francesa. Esses migrantes são em sua grande maioria pedreiros, carpinteiros, mestres de obras, armadores, pintores, faxineiras, babás, lavadeiras, cozinheiras e têm como destino final de sua prática migratória a cidade de Caiena, onde já contam com alguma rede de solidariedade (parentes e/ ou amigos) que lhe presta assistência até um estabelecimento definitivo.

Outros, migrantes sem documentos, chegam a permanecer um tempo prolongado na Guiana Francesa, mas em função das frequentes fiscalizações seu retorno pode acontecer a qualquer momento. Nesse grupo se encontram os garimpeiros, que se alojam em acampamentos nos garimpos clandestinos, sua residência se caracteriza pelo improviso e imprevisto, pois a vida 
de um garimpeiro é relativamente nômade, em virtude das seguintes possibilidades: 1) haver o esgotamento da jazida, o que motiva os garimpeiros a deslocarem-se em busca de outras; 2) a ocorrência de uma milícia se apropriar da jazida e os garimpeiros que não se ajustam a essa situação são expulsos, ou às vezes mortos; 3) ao intenso combate dos agentes institucionais franceses na desarticulação e destruição dos acampamentos e garimpos ilegais.

Assim sendo, homens, rios e ouro continuam a compor uma tríade da qual nascem as interações transfronteiriças, assinaladas por consensos e conflitos na fronteira Oiapoque-Guiana Francesa. A realidade é muito mais complexa do que as lentes conceituais que dispomos.

Procurando entender como ocorrem as movimentações na fronteira, compreendemos que diante das condições de vida enfrentadas pelos habitantes fronteiriços, eles estruturam experiências sociais. Em relação a isso, Haesbaert (2013) nos permite afirmar que para a população muito pobre, como a do Oiapoque, a continuidade espacial ainda é um dado fundamental em suas estratégias cotidianas de sobrevivência. Em tais circunstâncias, a sociodinâmica de Oiapoque se estende a Guiana Francesa, onde indivíduos singulares e coletivos acreditam encontrar elementos para satisfazer suas carências de subsistência. A prática de transcender a fronteira internacional implica na subversão do sentido de fronteira atribuído pelo Estado, qual seja: definir o que está sob seu domínio e o que está fora dele.

Muitos brasileiros que atravessam a fronteira em direção à Guiana Francesa acreditam que irão encontrar oportunidades de alcançar prosperidade: seja pelo euro, seja pelo ouro. Esse imaginário de que do outro lado existe uma vida melhor regeu e ainda rege a migração de brasileiros. Contudo, há outros interesses para transitar além e através da fronteira, podendo ser 
um passeio turístico, fazer vendas ou compras, realizar um trabalho ou acessar um serviço; ir para as ou vir das comunidades ribeirinhas; em síntese, a mobilidade e o deslocamento pelo rio fazem parte do cotidiano dessa população. Assim sendo, afirma-se que o relacionamento fronteiriço entre moradores de Oiapoque e seus vizinhos da Guiana Francesa foi se constituindo pela complementaridade.

Os contornos históricos da relação entre brasileiros de Oiapoque e guianenses da Guiana Francesa são constituintes de um modo de ser e perceber singular do viver num território fronteiriço. Os atores locais incorporam em seu dia-a-dia determinadas práticas, valores e normas que somente são possíveis de acontecer numa situação de vizinhança, que é reforçada pelo compartilhamento entre os grupos sociais - mesmo ocupando posições em lados opostos da fronteira internacional. Não se trata, portanto, de refletir sobre um recorte particular do espaço em si e por si, mas procurar suas características fundamentais, as quais preenchem uma das configurações da coletividade que nele se constituiu. Ao deslocarem-se pelo rio, os agentes constituem circuitos de mobilidade. Desse processo resulta o contorno que assume o território e a fronteira para a subjetividade desses agentes e que é distinto das qualidades que os Estados atribuem a essa mesma fronteira e território.

A movimentação na fronteira Oiapoque-Guiana Francesa se desenrolou livremente até fins da década de 1990, configurando um contexto interativo. Após esse período começaram os conflitos decorrentes do adensamento institucional francês coibindo à entrada de brasileiros em território guianense. A política de controle a imigração afetou de forma direta a mobilidade e aos deslocamentos de brasileiros no rio Oiapoque, ou seja, brasileiros em viagem pelo rio passaram a ser percebidos como migrantes em potencial. Desde então, a movimentação de pessoas passou a receber o peso da territorialidade estatal. Vale ressaltar que não há as mesmas restrições do lado brasileiro. 
O discurso estigmantizante sobre os imigrantes brasileiros como responsáveis pelos males que afligem a sociedade guianense ganhou força nos últimos anos e se vincula de forma direta ao clima violento e tenso nos garimpos clandestinos. As exigências crescentes de visto e documentação, a ameaça de detenção, os exercícios constantes da Gendarmerie, da Police aux Frontiéres e da Legião Estrangeira ao longo do rio Oiapoque, indicam uma política de segurança que corresponde ao postulado de que para os Estados o deslocamento e a mobilidade de pessoas são percebidos como temáticas vinculadas a sua soberania (REIS, 2007).

Considerando as características geofísicas do rio-fronteira Oiapoque e das condições das embarcações, os deslocamentos fluviais em alguns trechos exigem a transgressão do limite da fronteira. 0 nó górdio da questão está em dois trechos onde somente há um lugar com profundidade suficiente para comportar a travessia da embarcação, trata-se das cachoeiras Grand Roche e Caxiri (essa última somente assume essa peculiaridade no período de verão); sendo que a primeira está em território francês e a segunda em solo brasileiro.

É interessante a concepção de fronteira que possui agentes em movimento, em particular, quando se trata da travessia da Grand Roche, pois estes agentes defendem que;

(...) tem uma pedra bem aqui chamado Rocha, que esse delegado da Federal bate muito nessa tecla, que essa rocha fica no meio do rio então o rio é internacional, ela não é nem do Brasil e nem da França. Ela é uma pedra no meio do rio, quero que vocês batam foto lá. Lá tem uma rocha no meio do rio, coisa da natureza, tipo assim uma ilha, uma rocha pelada, uma 'pedrazona','monstra'; que você caminha por cima, passa pela França, carrega a canoa aqui e vai embora. Aí eu tenho os carregadores, mais de quarenta homens trabalha tudo legalizado aqui, tem a associação. Tem hora que você passa beirando aqui a ribanceira da França, tem hora que você passa glosando aqui o lado do Brasil. Na Grand Roche, 
essa Grand Roche é porque já aconteceram vários conflitos, lá o gendarme já pegaram [i.e. pegou] duas canoas minhas e já cortaram. (COMERCIANTE DO SETOR DE TRANSPORTE FLUVIAL, 2013, grifo nosso).

No território fronteiriço de Oiapoque sempre tem gente chegando, esperando, partindo; esses fenômenos denotam a historicidade de uma dinâmica populacional com sentido à vizinha Guiana Francesa. 0 perfil dessa mobilidade é variável tanto quanto são variáveis os objetivos dos indivíduos em trânsito. São pessoas em viagem para Saint-Georges, Caiena, Camopi, Vila Vitória, Vila Velha, Ilha Bela, Vila Brasil e/ou para os garimpos clandestinos espalhados pela Guiana Francesa. Comerciantes, catraieiros, carregadores e moradores nas comunidades de Ilha Bela e Vila Brasil são os atores que mais dependem do sistema de transporte fluvial no rio Oiapoque. A economia da cidade se estrutura em função das interações que mantêm com o território vizinho; em particular com a atividade de garimpeiros brasileiros que agem ilegalmente na extração de ouro ${ }^{12}$ na Guiana Francesa.

A logística do sistema de transporte fluvial começa na cidade de Oiapoque e se estende pelos lugares indicados no parágrafo anterior. São comerciantes que vendem as mercadorias, principalmente alimentos, bebidas, combustível, máquinas e equipamentos, cigarros, artigos de higiene. Os catraieiros ${ }^{13}$ que realizam o transporte através do rio Oiapoque, são carregadores fazem embarque, desembarque e transbordo na cachoeira Grand Roche. Assim sendo, é importante bem identificar esses agentes em

\footnotetext{
${ }^{12}$ Informação fornecida por morador de Ilha Bela referente aos garimpos na Guiana Francesa, quais sejam: Sikini (fechado), Capinzal (fechado), Quatá (fechado), Ocreia (fechado), Ipo 100, Rhataia, Tosti, Gabarri, D21, Sofia, Dorlin, Piti-Sul (todos em atividade). Ilha Bela-Oiapoque/AP, em 18 de julho de 2013.

${ }^{13}$ Cabe ressalvar que catraieiros e canoeiros executam a mesma tarefa que é pilotar as embarcações que fazem o transporte de passageiros de Oiapoque a Saint-Georges e a outras comunidades ribeirinhas. A denominação diferenciada refere-se ao tamanho das embarcações, menores catraias, maiores canoas. Nesse sentido, como a intenção é colocar em evidência os profissionais e para evitar muitas designações que pudessem provocar confusões adotou-se a denominação genérica de catraieiro.
} 
deslocamento e situar essa mobilidade no circuito mais polêmico que é Oiapoque-Ilha Bela-Vila Brasil.

Existem em Oiapoque três organizações que cuidam dos interesses dos catraieiros, a Cooperativa de Transporte Fluvial e Terrestre de Oiapoque (COMFCOI), a Associação de Pilotos Fluviais de Vila Vitória e a Associação de Canoeiros e Cantineiros do Alto do Rio Oiapoque. A profissionalização do catraieiro ocorre empiricamente, ou seja, para se tornar um catraieiro o aspirante deve iniciar seu aprendizado bem jovem, acompanhando catraieiros em suas viagens. Os pilotos em atividade ensinam aos mais jovens os caminhos líquidos do rio Oiapoque, o que significa ensinar a localização dos canais de passagem, sendo, desse modo, um saber da experiência, transmitido por treinamento.

Na cidade de Oiapoque os catraieiros compõem um grupo respeitado, pois são eles que asseguram o funcionamento de todo o sistema de transporte fluvial. Existem homens e mulheres no exercício da profissão, mas há predominância masculina; o rendimento médio mensal é em torno de $\mathrm{R} \$ 5$ mil podendo chegar a $\mathrm{R} \$ 7$ mil. Esse foi o grupo mais afetado pelas medidas institucionais francesas de controle ao trânsito pelo rio Oiapoque devido às apreensões, corte de catraias e queima de motores, bem como os embargos ao desembarque de brasileiros em Saint-Georges que prejudica os rendimentos referentes à travessia de passageiros. Quanto a isso assim se manifestou um catraieiro:

(...) nós contribuímos com o município, contribuímos com o Estado e contribuímos com a união e além de tudo: o desenvolvimento econômico do nosso município, da nossa fronteira Oiapoque, mas de $40 \%$ do desenvolvimento econômico é transportado pela classe catraieira. (CATRAIEIRO, 2013).

Os comerciantes compõem o outro grupo que tem significativa participação nas mobilizações locais contra as restrições fran- 
cesas ao tráfego no rio e a interdição à entrada de brasileiros em Saint-Georges. Eles são filiados à Associação Comercial de Oiapoque (ACOI), organização que está engajada nos diálogos estabelecidos localmente com representantes de Saint-Georges na busca por encontrar soluções para as situações de conflitos estabelecidas entre as duas coletividades que provocam prejuízos mútuos. Para os comerciantes, qualquer interferência na circulação das catraias no rio Oiapoque tem impactos sobre o comércio da cidade e, nesse sentido, a parceria com os catraieiros é estratégica.

Os comerciantes são enfáticos quando o assunto é a garimpagem ilegal de ouro na Guiana Francesa: "nós não temos problema de garimpo no Brasil (COMERCIANTE SETOR DA CONSTRUÇÃO CIVIL, 2013)"; atente-se que ele afirma não haver problemas de garimpo no Brasil, o que é uma estratégia discursiva para expressar que aqui a garimpagem de ouro não é ilegal; sendo, portanto, dessa perspectiva um problema da França e não do Brasil a existência de garimpos na Guiana Francesa. Inclusive no município de Calçoene, vizinho a Oiapoque existe um garimpo com mais de cem anos de atividade, fala-se do garimpo do Lourenço. Nessa direção, esses atores assim se posicionam:

Eu acho que eles [franceses] deveriam legalizar o garimpo deles com uma empresa francesa e que eles poderiam usar a nossa mão de obra. Legalizando o garimpeiro brasileiro, que entre documentado, que ele possa trabalhar, vim livremente visitar suas famílias e voltar. Eu acho que isso é uma alternativa [...]. 0 ouro ficaria lá [e] com certeza, eles [franceses] teriam perdas bem menores, porque são empresas francesas no caso, ou se fosse brasileira, mas eles vão colocar as regras deles, que o ouro seria vendido lá e aí teria a preservação do meio ambiente. (COMERCIANTE SETOR DA CONSTRUÇÃO CIVIL, 2013).

Os carregadores formam o terceiro grupo afetado pelo controle à mobilidade e ao deslocamento pelo rio Oiapoque, esses traba- 
lhadores têm origem de diversos estados, mais predominantemente do Pará e do Maranhão. São pessoas que possuem pouca escolaridade e não tem uma profissão especializada, tal como pedreiro, carpinteiro, marceneiro, as quais poderiam assegurar uma renda mensal acima do valor do salário mínimo. Grande parte deles era garimpeiro antes de ser carregador, e, conforme seus depoimentos, devido às dificuldades de viver e trabalhar em um garimpo, em especial o clandestino, decidiram largar a garimpagem e acabaram se fixando na cidade de Oiapoque, muitos por conta de ter estabelecido um relacionamento conjugal. A escolha de tornar-se carregador deveu-se a ser um ofício que não exige "nem profissão, nem estudo" como eles falam, mas garante um ganho mensal próximo a $\mathrm{R} \$ 4$ mil. 0 grupo está organizado na Associação dos Carregadores Autônomos de Oiapoque (ASCAO), o lema dessa associação é interessante: "O vigor dos braços e a sabedoria transportando o progresso". São esses trabalhadores que fazem o embarque e desembarque nos portos de Oiapoque e Saint-Georges, como também cuidam do transbordo das mercadorias na Grand Roche, onde atravessam a carga de um lado para o outro da grande pedra. Na hierarquia dos grupos, observou-se que os carregadores ocupam a posição mais inferior, e talvez em virtude disso negaram-se em gravar entrevistas. Entre eles existem controvérsias envolvendo o número de viagens realizadas por dia, pois seus maiores rendimentos estão no itinerário para Ilha Bela e Vila Brasil, mas especialmente no momento do transbordo na Grand Roche. As figuras 2 e 3 apresentam o momento em que catraieiros e carregadores brasileiros se encontram em território francês. 
MIGRAÇÃO E MOBILIDADE DE BRASILEIROS ATRAVÉS E ALÉM DA FRONTEIRA BRASIL-GUIANA FRANCESA

Figura 2 - Chegada da catraia na Grand Roche e desembarque

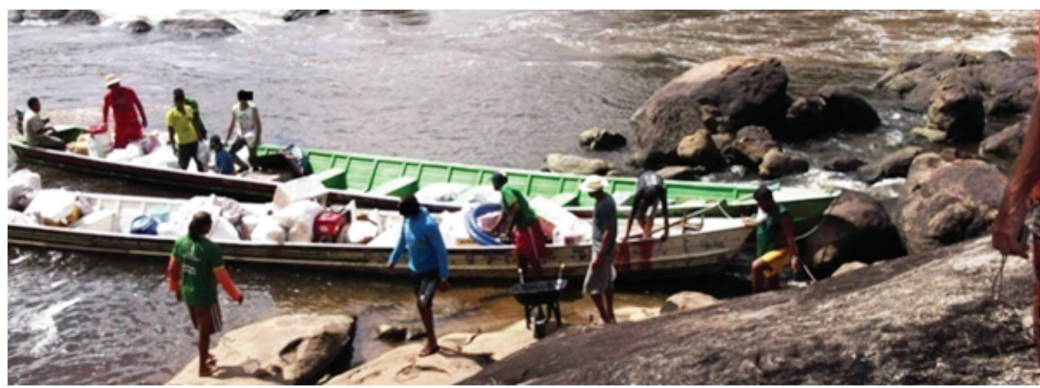

Fonte: Acervo pessoal Carmentilla Martins, julho de 2013.

Figura 3 - Carregadores atravessando a carga de um lado para o outro na Grand Roche
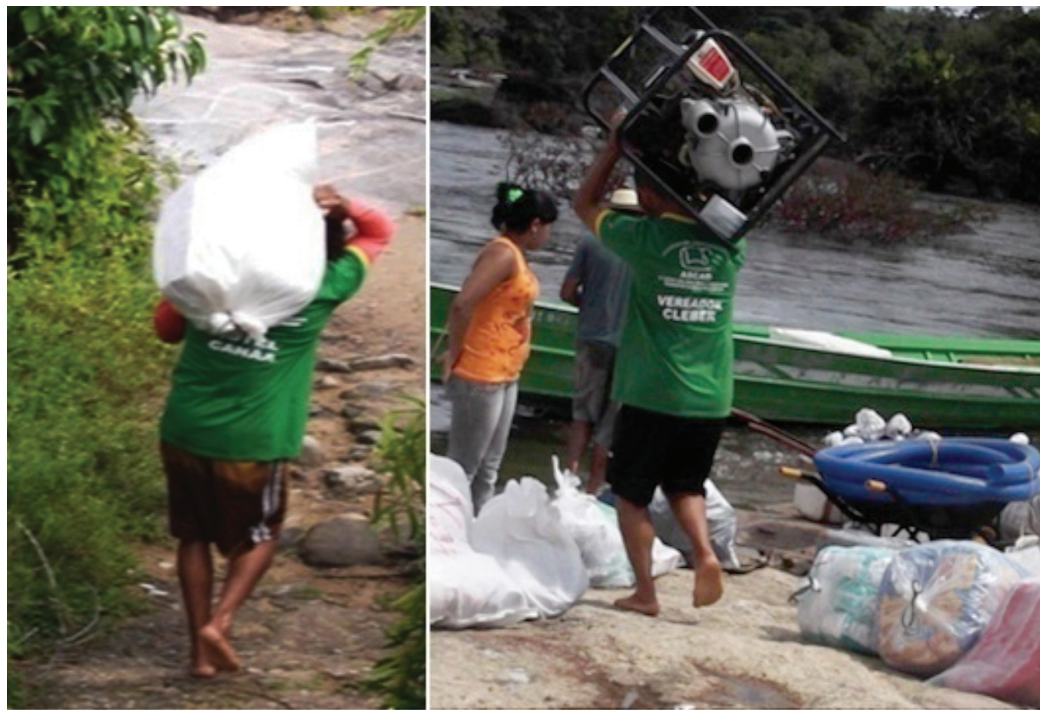

Fonte: Acervo pessoal de Carmentilla Martins, julho de 2013.

Quando ocorre o transbordo na Grand Roche o clima fica muito tenso, pois é nesse momento que pode haver abordagens da Gendarmerie, nas quais são feitas as apreensões de mercadorias (que são queimadas) e pessoas (levadas para serem deportadas depois). Nessa ocasião os policiais franceses cortam canoas e 
queimam motores; os catraieiros argumentam que isso corresponde a um grande prejuízo. Quando a Gendarmerie está vigiando a Grand Roche o transbordo das mercadorias e pessoas tem de ser feito por uma trilha em terra do lado brasileiro às margens das corredeiras do rio Oiapoque. Essa trilha tem um percurso um pouco maior que mil metros, sendo muito estreita, íngreme e perigosa; em se tratando de pessoa não habituada é praticamente impossível continuar a viagem. Pelas canoas seguem até mesmo veículos de vários tamanhos, inclusive máquinas pesadas. O proprietário de uma pousada em Vila Brasil relatou que para construir a pista de pouso e decolagens em Camopi os franceses trouxeram máquinas e tratores nas canoas que eram inclusive conduzidas por brasileiros.

É interessante que em muitas falas dos informantes, se apreende a mesma concepção de que os agentes institucionais franceses criam obstáculos ao trânsito de catraias pelo rio Oiapoque; no entanto, eles mesmos dependem dessa mobilidade e dos profissionais brasileiros, que são denominados de "considerados" devido ao conhecimento que têm acerca dos locais adequados de passagem. Essa assertiva lembra a referência de Bustamante (1989) sobre relações sociais através da fronteira México-Estados Unidos como pacíficas, desde que o mexicano seja o empregado, o vendedor; e o estadunidense seja o patrão, o cliente; ou seja, que exista uma relação de dominação-subordinação, de modo que mesmo pacíficas, implicam assimetrias de poder socioeconômico.

O último grupo afetado pelo controle da mobilidade e deslocamento pelo rio Oiapoque são os moradores das comunidades ribeirinhas de Ilha Bela e Vila Brasil. A primeira é um pequeno arquipélago de três ilhas e a outra é uma pequena comunidade ribeirinha. Ambas estão situadas nos limites do Parque Nacional Montanhas do Tumucumaque.

Os moradores de Ilha Bela e Vila Brasil organizaram-se em duas associações de moradores, esses grupos atuam em conjunto em 
favor de seus interesses, quais sejam: pela institucionalização do distrito de Vila Brasil que englobaria Ilha Bela, pela liberalização do trânsito pelo rio Oiapoque e pelo fim das interdições e apreensões realizadas pelos agentes institucionais, tanto brasileiros quanto franceses.

As restrições impostas à mobilidade e aos deslocamentos constituem processos sistêmicos de fechamento e de contenção. 0 que se observa é a construção do "paradigma da suspeita", que autoriza colocar em estado de suspeição qualquer indivíduo que possa a vir representar uma ameaça, mesmo que virtual. Essa condição é vivenciada pelos moradores de Ilha Bela e Vila Brasil, em especial a primeira, pois seus moradores são suspeitos de atuarem pela manutenção dos garimpos clandestinos. Indica-se nesse ponto a ambivalência da cooperação fronteiriça franco-brasileira, pois se de um lado propõe políticas de integração entre os territórios para o desenvolvimento local socioeconômico; de outro não consegue criar procedimentos ajustados às práticas dos agentes locais. Essa afirmação se exprime nas restrições institucionais à mobilidade e aos deslocamentos pelo rio Oiapoque, as quais se desdobram justamente numa exclusão socioeconômica, retirando daqueles o meio pelo qual acessam subsídios às suas necessidades existenciais.

\section{A complexificação das abordagens sobre migração e novos fenômenos}

As especificidades dos fenômenos de mobilidade e as dinâmicas da fronteira estudada nos força cada vez mais para a necessidade de se complexificar as abordagens que se restringem aos aspectos econômicos nos quais os imigrantes parecem indivíduos que tomam decisões desconectadas de suas relações sociais, apontando para a importância de se analisar as redes sociais no processo migratório (PORTES, 1995; SASSEN, 1998; RICHMOND, 1980) Segundo Boyd (1986), a utilização de redes 
sociais não é novidade na pesquisa sobre migração. Nos anos 1970, estudiosos analisaram os processos de redes de migração e o papel que os parentes e amigos desempenharam no fornecimento de informações e auxílio no processo migratório.

Tilly (1990), por exemplo, considera que deslocamentos populacionais não se sustentam somente por indivíduos que isoladamente decidem sair de seus países de origem, mas sim por grupos de pessoas ligadas por laços de amizade, conhecimento ou relações de parentesco. Afirma ainda este autor que os grupos de migrantes não podem ser classificados em trabalhadores qualificados ou trabalhadores não-qualificados. Completa afirmando que realmente algumas pessoas migram sozinhas, mas o fazem como participantes de um processo social.

Para alguns autores como Tilly (1990) e Massey (1997), os neoclássicos não conseguiram explicar satisfatoriamente certos questionamentos, como por exemplo: por que nos países pobres certos indivíduos emigram e outros não? Por que nestes mesmos países apenas uma minoria emigra? As respostas devem ser buscadas no papel desempenhado pelas redes sociais, pois são elas que vinculam pessoas e grupos nos dois pontos do circuito migratório (MARTES, 2000). Assim sendo, o foco de análise recai sobre as relações sociais responsáveis pela construção dos vínculos necessários para a emigração, pela veiculação do conjunto de informações e percepções que os indivíduos necessitam para sair de seus países.

Para Mansey (1990) redes migratórias compõem um conjunto de laços sociais que ligam comunidades de origem a específicos pontos de destino nas sociedades receptoras. Tais laços unem migrantes e não migrantes em uma complexa teia de papéis sociais complementares e relacionamentos interpessoais que são mantidos por um quadro informal de expectativas mútuas e comportamentos predeterminados. Já para Tilly (1990), as redes migram; as categorias permanecem e as redes criam novas 
categorias. As unidades efetivas da migração não são nem individuais nem domiciliares, mas sim conjuntos de pessoas ligadas por laços de amizade, parentesco e experiência de trabalho, que incorporam o país de destino nas alternativas de mobilidade por eles consideradas.

A migração de longa distância se vincula a muitos riscos: segurança pessoal, conforto, renda, relacionamento social, moradia provisória etc. Se nessas sociedades hospedeiras já existem parentes, amigos, vizinhos e colegas de trabalho, a confiança sobre as redes de informações interpessoais minimizam e diluem os riscos. Portanto, assim como acontece em outros fluxos migratórios, os imigrantes brasileiros em Caiena, por exemplo, utilizam-se desses recursos sociais (das redes) para diminuir as tensões iniciais. Sem esses acolhimentos grupais, essas migrações de longa distância são seriamente comprometidas.

Todos esses trabalhos demonstraram a importância das redes sociais na articulação dos processos migratórios, enfatizando a solidariedade no interior dos grupos migrantes como uma das características que configuram e sustentam as redes. Entretanto, tanto Boyd (1986), Tilly (1990) e Massey (1990) apontam para as ambiguidades dessas relações, pois a própria dinâmica da migração revela que os laços de parentesco, amizade, origem nacional comum são também permeados por conflitos. De forma curiosa, inúmeros depoimentos de brasileiros em Caiena atestam essas situações de falta de solidariedade. Uma das frases mais repetidas nas entrevistas feitas num documentário sobre a vida dos brasileiros na Guiana Francesa foi esta: "os brasileiros são uma classe muito desunida aqui".

Outro novo campo de investigação e de estudo, refere-se ao conceito de transnacionalização. Para abordar esses novos fluxos migratórios, Glick-Schiller, Basch e Blanc-Szanton (1992) realizaram uma breve incursão histórica sobre o fenômeno; e perceberam que a palavra migrante evoca imagens de ruptura per- 
manente, de abandono de velhos padrões, aprendizado difícil de uma nova língua e cultura. Para além dessa visão reducionista, baseadas tão-somente no enfoque melting pot (assimilação e aculturação), essas autoras perceberam em suas pesquisas, que os novos imigrantes mantêm múltiplas relações sociais entre o seu local de origem e a sociedade hospedeira. Os imigrantes passam a ser chamados de transmigrantes quando desenvolvem e mantém múltiplas relações - familiares, econômicas, sociais, organizacionais, religiosas e políticas que ampliam as fronteiras colocando em interrelação o global e o local. 0 enfoque transnacional enfatiza a emergência de um processo social que cruza fronteiras geográficas, culturais e políticas.

Vale ressaltar que em pesquisas recentes, a estratégia do "vai e vem" (aller/retour) é utilizada cada vez mais com frequência por imigrantes brasileiros na fronteira norte do Brasil. 0 que antes era visto como insucesso migratório, uma indecisão entre ficar na Guiana Francesa ou retornar para o Brasil, hoje é uma prática vista com naturalidade, pois existe nesta estratégia um cálculo racional, levando em conta custo/benefício. A partir de um cálculo racional alguns imigrantes brasileiros assumiram de vez que pertencem as duas sociedades e que estar no Brasil ou na Guiana faz parte de mesmo processo migratório. Desta forma, é cada vez mais comum depoimentos de brasileiros que não se importam mais de passar férias no Brasil ou mesmo passear na casa de familiares em períodos de curta duração. Esse fenômeno no Oiapoque é extremamente perceptível. Inclusive, observações feitas em campo atestam que alguns brasileiros que residem em Caiena, vão no fim de semana ao Oiapoque fazer compras, tomar cervejas e atrás de lazer. 0 que antes era exclusivo de turistas franceses/ guianenses, nos últimos anos tem sido uma prática de imigrantes brasileiros com seus familiares. Vale ressaltar ainda que quando a ponte binacional estiver liberada para os dois países e a BR-156 asfaltada completamente, é possível que esse fluxo de brasileiros chegue até a capital Macapá, pois tecnicamente uma viagem entre as duas cidades (Caiena e Macapá) levará em média 09 horas. 
Não podemos negar, realmente, que a maioria dos estudos migratórios de até há pouco tempo, tinha como pano de fundo o olhar voltado para os processos de assimilação e da perda de identidade cultural. Mas para Glick-Schiller, Basch e Blanc-Szanton (1992), os estudos clássicos de migração, ao elaborarem categorias tais como imigrantes temporários, retorno de imigrantes ou migrantes permanentes não perceberam que os imigrantes mantinham suas relações com a sociedade de origem, não em contradição, mas em conjunção com a sociedade hospedeira. Por isso, tais percepções não passaram do nível descritivo ao enfatizarem o caráter singular e distintivo de tais fenômenos, mais do que percebê-los como parte de um fenômeno global (SASAKI; ASSIS, 2002).

Na verdade, Sasaki e Assis acenam que os tempos são outros, e que agora o local e o global estão bem mais inter-relacionados que nos primeiros fluxos imigratórios do século XX. Isto não que dizer que os primeiros movimentos migratórios ocorreram sem que as comunidades de origem se modificassem; mas a natureza e a intensidade das modificações alteraram-se profundamente; pois o processo de globalização cultural interfere nas percepções e sentimentos individuais em relação a esta experiência.

As migrações internacionais recentes têm nos instigado a repensar as categorias com as quais as migrações e imigrantes vêm sendo analisados, demonstrando que estes processos de atravessar fronteiras devem contemplar múltiplos aspectos desse movimento. No caso da imigração de trabalhadores brasileiros para a Guiana Francesa, estas reflexões são extremamente importantes, para não corrermos o risco de limitar os imigrantes em categorias que não contemplam o fato de que são pessoas que se movem, têm projetos, desejos de ir, voltar, permanecer e reconstruir suas vidas atravessando estas múltiplas fronteiras, mesmo que de forma ilegal/clandestina. 


\section{Considerações Finais}

À guisa de conclusão, podemos dizer que o migrante, esta figura genérica definida sobretudo por sua mobilidade, é, na verdade, um sujeito múltiplo, ou melhor, a migração é um processo multifacetado (HAESBAERT, 2005). Estamos, contudo, convencidos de que a falta de oportunidade de trabalho é a condição primeira para alguém se lançar no mundo à procura de uma nova forma de vida, seja em Caiena, França ou Japão. Inclusive, como lembra Sayad (1998), "foi o trabalho que fez nascer o imigrante, que o fez existir; é ele quando termina, que faz morrer o imigrante, que decreta sua negação ou que o empurra para o não-ser". No entanto, se o trabalho é o ponto de partida para as migrações, as estratégias de permanências vão muito mais além dos contextos formais, da burocracia e das leis: por isso novas formas de sociabilidades são inventadas, redescobertas e redefinidas diariamente.

Vale lembrar que não há fala, não há discursos sobre imigração, mesmo os mais hostis, que não apelem para a moral, para as boas intenções e os bons sentimentos, enfim, para os interesses simbólicos a eles ligados. A imigração ainda não se configura como um objeto político propriamente autônomo, ou seja, um objeto exclusivamente político.

Dando forma a uma espécie de sociologia poética, Ianni (1999) fez um dos mais belos e inteligentes comentários sobre globalização, que tem a ver com este trabalho: "A sociedade global pode ser vista como uma imensa nebulosa vagando pelo espaço e tempo, como se estivesse ao acaso, sem norte ou extraviada, anônima, inominada, em busca de significados" (IANNI, 1999, p. 23). Foi neste ambiente de pura sensibilidade histórica, sociológica e política que refletimos o contexto fronteiriço, a questão das migrações e sua circularidade/mobilidade entre Brasil e França na fronteira norte do Brasil; enfim, sobre a saga de milhares de brasileiros que tentam driblar seus próprios destinos em terras alheias. 


\section{Referências}

ASSIS, Gláucia de Oliveira, SASAKI, Elisa Massae. Teoria das Migrações Internacionais in ENCONTRO NACIONAL DA ABEP, 22. Anais... GT de Migração, 2000.

BARTH, F. Les groupes ethniques et leurs frontières. In: POUTIGNAT, P.; STREIFF-FENART, J. (Orgs.). Théories de l'ethnicité. Paris: Presses Universitaires de France, 1995, p. 203-249.

BRASIL/PORTALODM (2015). Acompanhamento Municipal dos Objetivos do Milênio. Disponível em: <www.portalodm.com.br/relatorios/PDF/gera_PDF. php?cidade $=2320>$. Acesso em: 24 set. 2015.

CATRAIEIRO. [Sobre a cooperação fronteiriça Brasil-França]. Oiapoque, 18 jul. 2013. Depoimento concedido a Carmentilla Martins.

COMERCIANTE DO SETOR DE CONSTRUÇÃO CIVIL. [Sobre a cooperação fronteiriça Brasil-França]. Oiapoque, 15 jul.2013. Depoimento concedido a Carmentilla Martins.

FARRAUDIERE, Y. Ecole et société en Guyane française: scolarisation et colonisation. Paris: L'Harmattan, 1989.

GRENIER, Georges-Marie (Direct.). Guyane-Amapá Mieux structurer les territoires pour intensifier lês échanges. Guyane: CEROM; AFD; IEDOM; INSEE, 2011.

HAESBAERT, Rogério (2013). Regiões Transfronteiriças e redes 'Brasileiras no Mercosul. Disponível em:<observatoriogeograficoamericalatina.org.mx/ egal8/Geografiasocioeconomica/Geografiaregional/04.pdf>. Acesso em: 21 set. 2013.

IANNI, Octávio. A sociologia para o século XXI. In: CONGRESSO BRASILEIRO DE SOCIOLOGIA, 9. Pelotas, Anais. EDUCAT, 1999.

INSEE (Institut National de la Statistique et des Études Économiques). Guyane: Rapport anuel de 2011. Paris: PRIM, 2012.

JOLIVET, M.-J. La question créole: essai de sociologie sur la Guyane française. Paris: ORSTOM, 1997. (Collection Mémoires, n. 96).

MAM-LAM-FOUCK, S. (Org.). Lidentité guyanaise en question: les dynamiques interculturelles en Guyane française. Kourou: Ibis rouge éditions, l'Harmattan, 1997.

MAM-LAM-FOUCK, Serge. Historie générale de la Guyane Française: les grands problèmes guyanais; permanense et évolution. Cayenne: Íbis Rouge; presses Universitaires Créole/GEREC, 1996. 
MASSEY, Douglas, et al. Migration, ethnic mobilization and globalization - causes of migration. In: GUIBERNAU, Montserrat; REX, John (eds.). The Ethnicity reader - nationalism, multiculturalism and migration. UK, Polity Press, 1997. p. 257-269.

OLIVEIRA, Antonio Tadeu Ribeiro de. Algumas abordagens teóricas a respeito do fenômeno migratório. In: OLIVEIRA, Antonio Tadeu Ribeiro de;Oliveira, Luiz Antonio Pinto de (Orgs.). Reflexões sobre os deslocamentos populacionais no Brasil. Rio de Janeiro: IBGE, 2011. (Estudos e Análises, Informação Socioeconômica, 1). Disponível em: <www.ibge.gov.br/home/estatistica/populacao/ reflexoes_deslocamentos/deslocamentos.pdf>. Acesso em: 11 ago. 2011.

PINTO, Manoel de Jesus Souza. O Fetiche do Emprego. Um estudo sobre as relações de trabalho de brasileiros na Guiana Francesa. Belém: NAEA, 2012.

PORTES, Alejandro. Immigrant in America - a portrait. Los Angeles: University of California Press, 1990.

PORTO, Jadson Luís Rebelo. SILVA, Gutemberg de Vilhena. De Periferia a Espaço Estratégico: A Construção da Condição Fronteiriça Amapaense. Anais do 5o Workshop da Associação Portuguesa para o Desenvolvimento Regional. Coimbra, Universidade de Coimbra, 2010

RICHMOND, Anthony H. Immigration and ethnic conflict. London, MacMilan Press, 1988. BOYD, Monica. Family and personal networks in international migration: recent developments and new agenda in International Migration Review, v. 23, n. 3, p.638-670, Fall, 1989.

RODRIGUES, Francilene. Migração transfronteiriça na Venezuela. Estudos Avançados/USP, São Paulo, v. 20, n. 57, maio/ago. 2006.

SANTOS, Paula Gabriele Sena dos. A (ultra) periferia do platô das guianas: novos planejamentos para novos usos da fronteira Amapá-Guiana Francesa (1992-2012). Dissertação de Mestrado, Programa de Mestrado em Desenvolvimento Regional Universidade Federal do Amapá, Macapá, 2013.

SAYAD, Abdelmalek, A imigração ou os paradoxos da alteridade. São Paulo: Edusp, 1998.

SENRA, Kelson Vieira. Políticas e instituições para desenvolvimento econômico territorial. 0 caso do Brasil. Santiago de Chile: Naciones Unidas, 2010. Disponível em: <www.eclac.cl/ilpes/publicaciones/xml/3/38883/S8DT_ L3192_p.pdf>. Acesso em: 30 abr. 2013.

SILVA, Gutemberg de Vilhena . Cooperação transfronteiriça entre Brasil e França. Ensaios e expectativas nesse século XXI. Tese de Doutorado. Programa de Pós-Graduação em Geografia, Universidade Federal do Rio de Janeiro, 2013. 


\section{MIGRAÇÃO E MOBILIDADE DE BRASILEIROS ATRAVÉS E}

ALÉM DA FRONTEIRA BRASIL-GUIANA FRANCESA

SIMMEL, Georg. Questões fundamentais da sociologia: indivíduo e sociedade. Tradução de Pedro Caldas. Rio de Janeiro: Jorge Zahar Ed., 2006.

SOARES, Ana Paulina. Travessia: análise de uma situação de passagem entre Oiapoque Guiana Francesa. 1995. 112 f. Dissertação (Mestrado em Geografia) - Faculdade de Letras, Filosofia e Ciências Humanas, Universidade de São Paulo, 1995. Disponível em: <www.pos.fflch.usp.br/node/13424>. Acesso em: 1 jun. 2010.

TILLY, Charles. Reconsidered transplanted networks. In YANS MAC LAUGHLIN, Virginia. Immigration reconsidered. NY: Oxford,1990.

TOSTES, José Alberto. Planos Diretores do Amapá: A experiência do município de Laranjal do Jarí. Uma contribuição para o desenvolvimento regional. Macapá: Unifap, 2010.

Recebido em 26/12/2015

Aprovado em 30/12/2015 